\title{
Update of the Portuguese Familial Hypercholesterolaemia Study
}

\author{
A.M. Medeiros ${ }^{a, b}$, A.C. Alves ${ }^{a, b}$, V. Francisco ${ }^{a, b}$, \\ M. Bourbon ${ }^{\mathrm{a}, \mathrm{b}, *}$, on behalf of the investigators of the Portuguese FH Study \\ a Grupo de Investigação Cardiovascular, Unidade de IEDD, Departamento de Promoção da Saúde e Doenças Crónicas, \\ Instituto Nacional de Saúde Dr Ricardo Jorge, Av. Padre Cruz, 1649-016 Lisboa, Portugal \\ ${ }^{\mathrm{b}}$ BioFIG, Center for Biodiversity, Functional and Integrative Genomics, Lisboa, Portugal
}

\section{A R T I C L E I N F O}

\section{Article history:}

Received 1 March 2010

Received in revised form 2 July 2010

Accepted 12 July 2010

Available online $\mathrm{xxx}$

\section{Keywords:}

Familial Hypercholesterolaemia

Low density lipoprotein receptor

Cholesterol

Coronary heart disease

Mutation

Cascade screening

\begin{abstract}
A B S T R A C T
The main aim of the Portuguese Familial Hypercholesterolaemia Study is to identify the genetic cause of hypercholesterolaemia in individuals with a clinical diagnosis of Familial Hypercholesterolaemia (FH). A total of 1340 blood samples were collected from 482 index patients and 858 relatives with the collaboration of clinicians from several hospitals all over the country. The genetic diagnosis of FH in this study is based on the analyses of three genes: $L D L R, A P O B$ and PCSK9. In the last 10 years, the Portuguese FH Study identified a genetic defect in a total of 171 index patients, corresponding to an overall of $48 \%$ of the total received cases with clinical diagnosis of $\mathrm{FH}$. Although the Simon Broome FH register criteria have been adapted to our study, 59 patients that did not fulfil all criteria were included in the study and a mutation causing disease was identified in 8 of these patients. In the LDLR gene were found 80 different mutations in 165 unrelated index patients: 159 heterozygous, 3 compounds heterozygous and 3 true homozygous. The APOB p.Arg3527Gln and the PCSK9 p.Asp374His mutation were not found in any of our patients since our last report, but a novel mutation in the APOB gene, predicted to cause a single amino acid substitution p.Tyr3560Cys, was found in one patient. The cascade screening in relatives of these 171 index patients allowed the identification and genetic characterization of a total of $404 \mathrm{FH}$ patients in Portugal.
\end{abstract}

(c) 2010 Elsevier Ireland Ltd. All rights reserved.

\section{Introduction}

Familial Hypercholesterolaemia (FH) is an autossomal dominant disorder clinically characterized by high levels of LDL-associated cholesterol in plasma. This accumulation causes its deposition on arteries and tendons leading to accelerated atherosclerosis and increased risk of premature coronary heart disease (CHD) [1].

FH usually results from mutations in three different genes involved in lipid metabolism [2]. These include, most commonly, mutations in the low density lipoprotein receptor gene (LDLR), less commonly in the apolipoprotein B (APOB) gene and rarely in the proprotein convertase subtilisin/kesin type 9 (PCSK9) gene [3]. At present, more than 1000 mutations have been described worldwide in the LDLR gene (http://www.ucl.ac.uk/fh) and the residual LDL receptor activity varies considerably between those [4]. Mutations in exons 26 and 29 of the APOB gene have been identified in $\mathrm{FH}$ patients, the most common of which is the nucleotide change c. $10708 \mathrm{G}>\mathrm{A}$, predicted to lead to the amino acid substitution p.Arg3527Gln [5]. From the PCSK9 mutations reported worldwide

\footnotetext{
* Corresponding author. Tel.: +351 917202207; fax: +351 217526400

E-mail address: mafalda.bourbon@insa.min-saude.pt (M. Bourbon).
}

[6] none was found in the Portuguese population except the mutation, p.Asp374His, located at the same codon as the p.Asp374Tyr described previously [6], but leading to a different amino acid substitution.

In 1999, it was first established by the Portuguese FH Study, a DNA diagnosis for patients with clinical diagnosis of $\mathrm{FH}$ and cascade screening in relatives of the affected index patients. This study has been based at the National Institute of Health, Lisbon, where the biochemical characterization and DNA diagnosis have been performed with no costs for the patient/medical institution partly due to a collaboration established in 2006 with the Portuguese Society of Cardiology. The number of index patients has expanded significantly since then due an increasing network of 24 clinicians located throughout several hospitals in Portugal. The genetic diagnosis of FH is performed in three phases and an optional fourth phase. Phase I comprises screening for the common mutations in APOB gene and analysis of LDLR gene. Phase II includes identification of large rearrangements in the LDLR gene using MLPA technique. Phase III consists in screening of PCSK9 gene and is only performed if no mutation was found in phases I and II. Phase IV is only performed when putative splicing mutations, not described before or without functional studies, are found. RNA from peripheral blood mononuclear cells (PBMC) is extracted and the cDNA is analysed to identify the effect of the alteration on the splicing mechanism. 
Table 1

New LDLR mutations identified in the Portuguese FH patients since last mutation report in 2008.

\begin{tabular}{|c|c|c|c|c|}
\hline Location & Nucleotide change & Protein & Predicted effect & References \\
\hline Promoter & c. $-135 \mathrm{C}>\mathrm{G}$ & & LDLR not produced & [9] \\
\hline Promoter & c. $-13 A>G$ & & LDLR not produced & Novel \\
\hline Exon 2 & [EX2_3del] & & Large deletion of 2 exons & Novel $^{\mathrm{a}}$ \\
\hline Intron 2 & c. $190+4$ insTG & & Splicing error & Novel \\
\hline Exon 3 & c. $274 \mathrm{C}>\mathrm{G}$ & p.Gln92Glu & & [10] \\
\hline Exon 4 & c. $427 \mathrm{~T}>\mathrm{C}$ & p.Cys143Arg & & [11] \\
\hline Exon 4 & c. $473 C>G$ & p.Ser158Cys & & Novel \\
\hline Exon 4 & c. $502 \mathrm{G}>\mathrm{C}$ & p.Asp 168 His & & [12] \\
\hline Exon 4 & c. $551 \mathrm{G}>\mathrm{A}$ & p.Cys184Tyr & & [13] \\
\hline Exon 4 & c. $590 \mathrm{G}>\mathrm{T}$ & p.Cys197Phe & & [14] \\
\hline Exon 8 & c. $1176 \mathrm{C}>\mathrm{A}$ & p.Cys392X & Stop codon & [15] \\
\hline Exon 9 & c. $1322 \mathrm{~T}>\mathrm{C}$ & p.Ile441Thr & & [16] \\
\hline Intron 9 & c. $1359-5 \mathrm{C}>\mathrm{G}$ & & Splicing error & [9] \\
\hline Exon 10 & c. $1325 A>G$ & p.Tyr442Cys & & [17] \\
\hline Exon 10 & c. $1403 T>A$ & p.Val468Asp & & Novel \\
\hline Exon 11 & c. $1599 G>A$ & p.Trp533x & Stop codon & [18] \\
\hline Exon 12 & c.1756delT & p.Ser586GlnfsX78 & Truncated peptide & Novel \\
\hline Intron 12 & c. $1846-1 \mathrm{G}>\mathrm{A}$ & & Splicing error & [12] \\
\hline Exon 13 & c. $1876 G>A$ & p.Glu626Lys & & [19] \\
\hline Exon 13 & c.1936delC & p.Leu646TyrfsX18 & Truncated peptide & Novel \\
\hline Exon 13 & c. $1966 \mathrm{C}>\mathrm{A}$ & p.His656Asn & & {$[20]$} \\
\hline Exon 14 & c. $2054 \mathrm{C}>\mathrm{T}$ & p.Pro685Leu & & [21] \\
\hline Intron 14 & c. $2140+1 G>A$ & & Splicing error & [22] \\
\hline Exon 15 & c.2146G >A & p.Glu716Lys & & Novel \\
\hline Exon 16 & [EX16_18del] & & Large deletion of 3 exons & Novel $^{\mathrm{a}}$ \\
\hline Exon 16 & c. 2385 delC & p.Pro795ProX20 & Truncated peptide & Novel \\
\hline Exon 16 & c. $2389 \mathrm{G}>\mathrm{T}$ & p.Val797Leu & Splicing error & [9] \\
\hline
\end{tabular}

Mutations not described before are in bold.

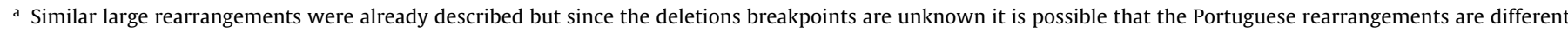
from the previously described.

\section{Methods}

\subsection{Patients}

A total of 1340 blood samples were collected from 482 index patients and 858 affected and unaffected relatives. The 482 index patients (318 adults and 164 children) were referred to our lab following the Simon Broome criteria for $\mathrm{FH}$, as presented before $[7,8]$.

\subsection{Biochemical characterization}

The biochemical parameters, including total cholesterol, LDLcholesterol, HDL cholesterol, triglycerides, apolipoprotein AI, apolipoprotein B and lipoprotein (a), were determined for all individuals in an Hitachi 911 (Boehringer, Mannheim, Roche) until 2007 and in Cobas Integra 400 plus (Roche) since then, by an enzymatic colorimetric method.

\subsection{DNA isolation}

Genomic DNA was isolated from whole blood EDTA samples, using the Wizard ${ }^{\circledR}$ Genomic DNA Purification kit (Promega) according to the manufacturer's instruction.

\subsection{DNA analysis}

The promoter region and the 18 exons of the LDLR gene were amplified from genomic DNA by polymerase chain reaction (PCR) and screened for sequence alterations using denaturing high pressure liquid chromatography (DHPLC) and automated sequencing. Large rearrangements in the LDLR gene were identified by multiplex ligation-dependent probe amplification (MLPA) technique using the SALSA ${ }^{\circledR}$ MLPA $^{\circledR}$ kit P062 LDLR (MRC-Holland). Screening for the common mutations in the APOB gene was performed by PCR amplification and direct sequencing of exons 26 and 29. The
12 exons of PCSK9 gene were amplified by PCR and analysed by direct sequencing. All the described techniques were performed as reported before [8].

\section{5. $R N A$ extraction and reverse transcriptase $(R T)$ reaction}

PBMC were isolated from $8 \mathrm{ml}$ of fresh blood collected in CPT tube (cell preparation tube with sodium citrate, BD Vacutainer ${ }^{\circledR}$ ) by centrifugation for $30 \mathrm{~min}$ at $2800 \mathrm{rpm}, 4^{\circ} \mathrm{C}$ (separation of PBMC must occur during the first $2 \mathrm{~h}$ after collection). The upper layer containing plasma and PBMC was transferred to a $15 \mathrm{ml}$ falcon tube. The PBMC were obtained by centrifugation for $10 \mathrm{~min}$ at $1400 \mathrm{rpm}$, $4{ }^{\circ} \mathrm{C}$. The mononuclear cells (pellet) were then washed with PBS by centrifugation as above. Total RNA was extracted with the RNeasy ${ }^{\circledR}$ Mini Kit (Qiagen), including the optional DNase I incubation as described in the kit protocol. This procedure yielded $6.5-20 \mu \mathrm{g}$ of total RNA (200-600 $\mathrm{ng} / \mu \mathrm{l})$. To prepare cDNA, $1 \mu \mathrm{g}$ of RNA was reverse transcribed with TaqMan Reverse Transcription (Applied Biosystems) as described in the kit protocol [9].

\section{6. $R T-P C R$ and analysis of PCR fragments}

Amplification of the cDNA fragments of interest was performed in a T3000 thermocycler (Biometra) as reported before [9].

\section{Results}

\subsection{Clinical analysis}

Biochemical data referring to total cholesterol and LDLcholesterol, for the FH patients genetically identified in Portugal (before treatment values were only available for 351 Portuguese FH patients) is shown in Supplementary Fig. S1A.

Coronary heart disease is present in 49 of the total Portuguese FH patients genetically identified (17\% of the adult FH patients). Premature CHD analysis of the $49 \mathrm{FH}$ patients distributed according 
to age group is shown in Supplementary Fig. S1B. From the analyses of clinical questionnaires 64 premature deaths have occurred in the reported families $(55.0 \pm 14.0$ years $)$.

\subsection{Molecular analysis}

From the 482 index patients received only 359 patients have their molecular study completed, so the results presented are relative to these patients.

\subsubsection{LDLR gene}

A total of 80 mutations were identified in 165 index patients participating in the Portuguese FH Study, 34 being exclusive to the Portuguese population.

Since our last report [8] 27 different mutations have been found, 10 of which have not been reported previously (Table 1). These 27 mutations found in the Portuguese FH patients include 2 mutations in the promoter region, 13 missense mutations, 2 nonsense mutations, 5 splice site mutations, 3 small deletions and 2 large deletions.

Six index patients were found to carry two defective LDLR alleles. Three presented the same mutation in both alleles and three presented different mutations in the two defective alleles, four of these patients had been previously reported and one is a true homozygous for the p.Arg406Trp, an already described mutation [8]. The new patient who was found to be compound heterozygous for p.Asp224Asn and p.Glu716Lys presented a severe phenotype. This patient and his daughter carried the same allele with p.Asp224Asn mutation but his daughter did not inherit the allele carrying p.Glu716Lys (Fig. 1) confirming that the two mutations are not on the same allele and that the index patient is a compound heterozygous. The p.Glu716Lys variation has not been reported before and requires in vitro confirmation of its pathogenic effect.

The screening of 443 individuals in these 165 families identified in the Portuguese FH Study, lead to the additional identification of 226 genetically diagnosed $\mathrm{FH}$ patients.

Index patients in whom no mutation was found in the APOB and LDLR genes were analysed by MLPA in order to identify possible large rearrangements in the LDLR gene. Two large deletions were identified in two unrelated patients. One of the large deletions was found in one family with a severe phenotype (Supplementary Fig. S2); a 5-year-old girl and her father with premature CHD carried the same allele with a deletion of the $3^{\prime}$-end of the LDLR gene comprising exons 16-18. The other large deletion, of exons 2 and 3 , was found in a child, his brother and father with a severe phenotype and a family history of premature CHD. Both large deletions are novel in the Portuguese population.

\subsection{2. $A P O B$ gene}

The APOB p.Arg3527Gln mutation was found in three unrelated index patients as reported previously [8]. Screening relatives in two of these families lead to the identification of six more patients carrying this APOB mutation.

One novel mutation in the APOB gene, predicted to cause a single amino acid substitution p.Tyr3560Cys, was found in one child with ancestors in Cape Verde Islands, an ex-Portuguese colony. This mutation has been reported before [22]. Unfortunately this patient had no relationship with both parents and so it was not possible to identify other relatives.

\subsubsection{PCSK9 gene}

The PCSK9 gene analysis was performed for all patients without LDLR or APOB mutations, 48 patients have been fully studied and the remaining were studied for alterations in exons 2, 3, 4, 5 and 7. The only mutation identified in this gene, p.Asp374His, has

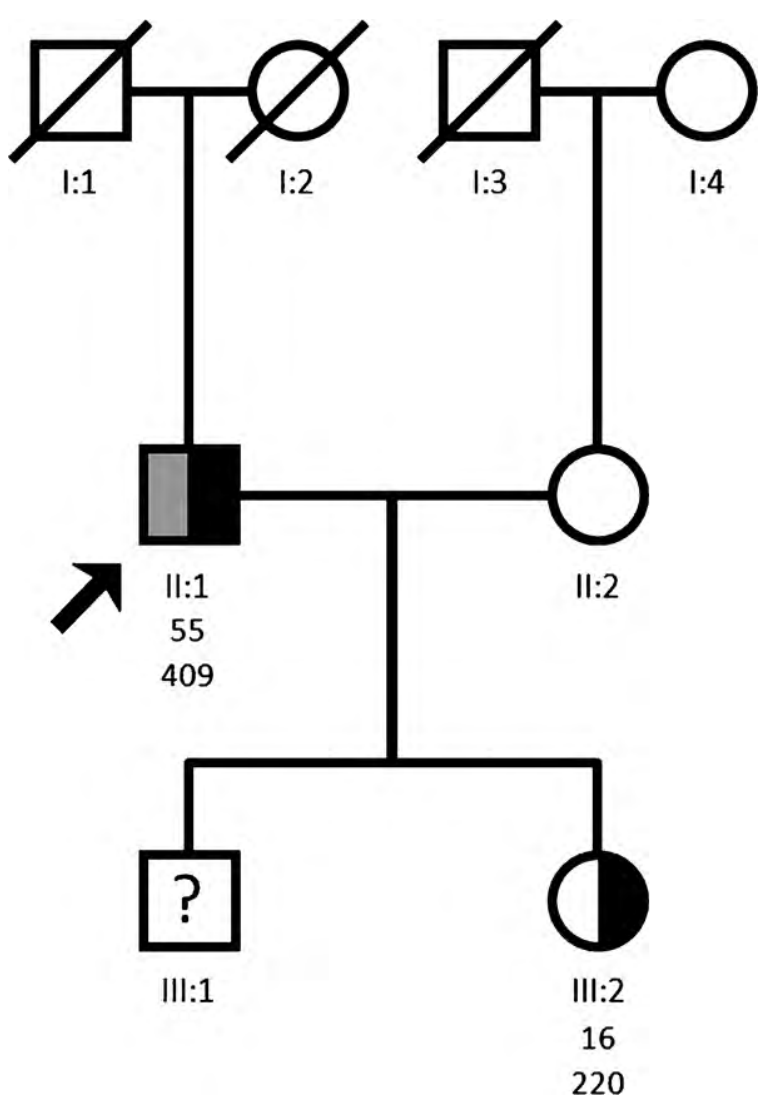

Fig. 1. Pedigree of the compound heterozygous patient carrying p.Asp224Asn and p.Glu716Lys mutations. The arrow indicates the index patient. Age in years and total cholesterol values in $\mathrm{mg} / \mathrm{dl}$ are shown below each symbol. Half shaded symbol black correspond to p.Asp224Asn mutation. Half shaded symbol grey corresponds to p.Glu716Lys mutation. Open symbols represent individuals not available for the study. Open symbol with question mark represent individual with clinical FH but that was not available for the study.

been reported previously by our group [8] and was only present in three patients of the Portuguese FH Study. Five novel variants were found in possible $\mathrm{FH}$ patients without mutations in LDLR or APOB gene: c. $-73 A>G$ ( 1 patient), c. $-67 C>A$ ( 1 patient), c. $400-22 C>A$ (9 patients), c. $1181-53 \mathrm{~T}>\mathrm{C}(6$ patients $)$ and c. $1180+22 \mathrm{~T}>\mathrm{C}(1$ patient $)$. The unique variants need further characterization to analyse the possible effect in cholesterol metabolism.

\subsection{4. cDNA analysis of putative splicing mutations}

Blood samples for mRNA extraction and cDNA analysis were obtained from four index patients. Two of these variants, c. $1060+1 \mathrm{G}>\mathrm{A}$ and c. $2547+1 \mathrm{G}>\mathrm{A}$, caused total exon skipping, one caused retention of 10 nucleotides of intron 5 (c.818-2A>G) and variant c.190+4insTG caused retention of 2 nucleotides of intron 2 (Fig. 2). All putative splicing mutations analysed are predicted to create a premature stop codon. Alteration c.1060+1G>A causes skipping of exon 7 generating a complete different protein from exon 6 forward and a premature stop codon at aa 779. Alteration c. $2547+1 \mathrm{G}>\mathrm{A}$ causes skipping of exon 17 and a premature stop codon at aa 805 . Alteration c.818-2A $>\mathrm{G}$ causes the retention of $10 \mathrm{bp}$ of intron 5 generating a premature stop codon at aa 303. Alteration c.190+4insTG involved activation of a novel splicing-donor site (GT) at IVS2+3+4 (instead of IVS2+1+2), resulting in the defective splice out of intron 2 , leading to the reading-through of exon 2 plus the following intronic 2 bp sequence, generating a complete different protein from exon 2 forward and a premature stop codon at aa 206 (Fig. 2). 
(A)

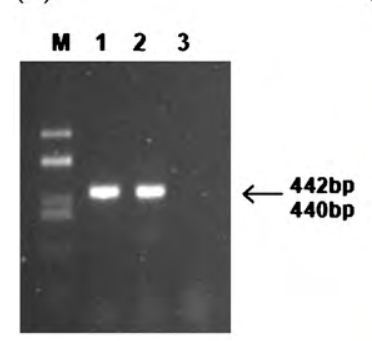

(B)

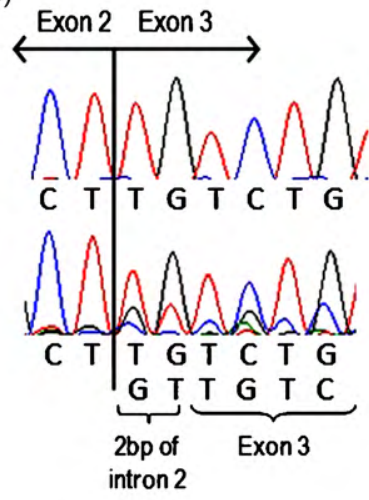

(C)

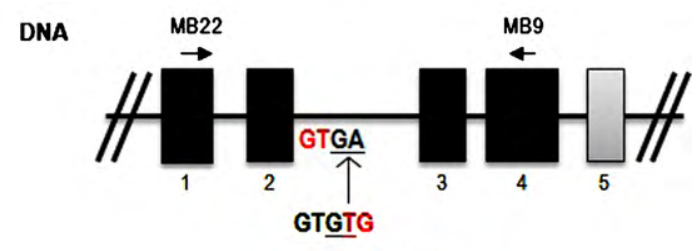

Normal
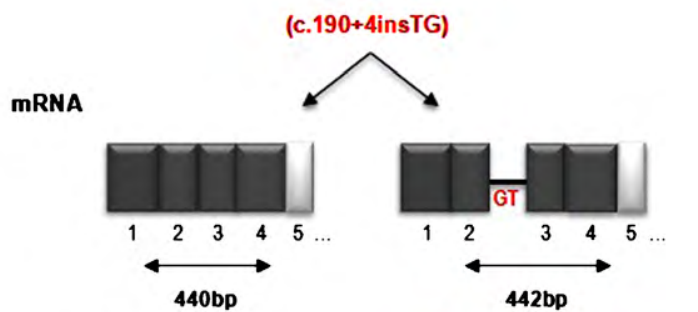

Normal transcript

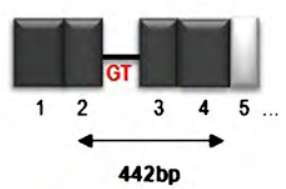

Mutant transcript

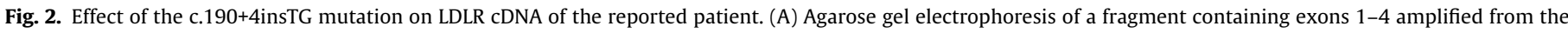

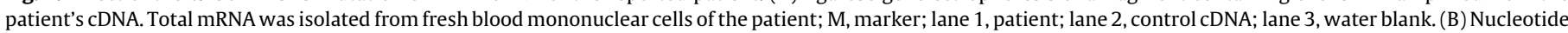

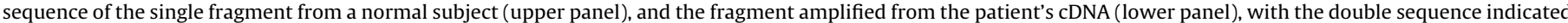
below. (C) Diagram showing the location of primers used and the two fragments obtained (MB22: GGCTGGAAATTGCGCTGGAC and MB9: CTGGCGGGACCACAGGTGAGC).

\section{Discussion}

In 1999 a lipid network was established for the Portuguese FH Study and since then DNA based diagnosis has been set up to study patients with a clinical diagnosis of $\mathrm{FH}$. The screening protocol used in this study has lead to the genetic identification of a total of 171 index patients, corresponding to an overall identification of $48 \%$ of the received cases with clinical diagnosis of $\mathrm{FH}$. The low percentage of index cases genetically identified in our population can be due to several reasons but, the one reason is the definition of the criteria for inclusion in the study that is not always followed by the rule. Following the Simon Broome Registry criteria, based in a family history of hypercholesterolaemia and a cut off value for total cholesterol of $260 \mathrm{mg} / \mathrm{dl}$ or LDLc of $155 \mathrm{mg} / \mathrm{dl}$ for children under 16 , and a cut off value of $290 \mathrm{mg} / \mathrm{dl}$ or LDLc of $190 \mathrm{mg} / \mathrm{dl}$ for adults, in $45 \%$ of the children and in $51 \%$ of adults studied, a mutation causing disease was identified. Since patient referral to the Portuguese FH Study has been very weak (it is estimated that $80 \%$ of $\mathrm{FH}$ patients are not even clinically identified), it was decided to study all the patients referred by the clinicians as long as they fulfilled the criteria of having a total cholesterol above the 95th percentile for age and sex and a family history of hypercholesterolaemia. In fact, of the 8 children studied with cholesterol between 200 and $260 \mathrm{mg} / \mathrm{dl}$ (or LDLc between 120 and $155 \mathrm{mg} / \mathrm{dl}$ ), none had a disease-causing mutation, while in the adult group, of the 34 patients with total cholesterol values between 240 and $290 \mathrm{mg} / \mathrm{dl}$ ( or LDLc of 144-190 mg/dl), a mutation was identified in 5 patients, none of these patients had premature CHD. Also 3/17 patients with triglycerides above $250 \mathrm{mg} / \mathrm{dl}$ and premature CHD, had a mutation causing disease; 6 of these patients had also premature CHD but a mutation causing disease was not found. This means that a mutation was found in $14 \%(8 / 59)$ of the patients that did not fulfill the Simon Broome criteria. Even so, since the genetic diagnosis of $\mathrm{FH}$ is still time consuming and expensive it was decided that Portugal will continue to use Simon Broome criteria since it is more cost effective. When other less expensive and less time consuming technologies are available this decision will be revised.

For $52 \%$ of the patients it was not possible to identify a mutation in any of the three genes analysed. One possible explanation is that the underlying gene defect causing $\mathrm{FH}$ in these patients is in a non-coding region of the LDLR gene that may affect its expression or RNA processing, not detectable by the methodologies used in this study. The other explanation is that the defect lies in another gene involved in LDLR function, regulation or LDL metabolism. Some patients can also be misdiagnosed and instead of FH can have familial combined hyperlipidaemia (FCHL) which is thought to be a dominant condition associated with hyperlipidaemia and premature CHD, with very few candidate genes identified. Since 51/188 did not fulfil the Simon Broome clinical criteria for FH it is also possible that these patients are being clinically misdiagnosed with $\mathrm{FH}$. Our group intends to examine these options in the future in the genetically unidentified families of the Portuguese FH Study.

The large rearrangements detected by the MLPA methodology are being confirmed by long PCR but when deletions occur at the 5 '-end or 3'-end of the gene confirmation is more difficult. MLPA is a simple and rapid method for detecting large rearrangements in the LDLR gene and our results support the reliability of MLPA for genetic diagnostic and is our opinion that should be included in the methodology for genetic testing of $\mathrm{FH}$ as suggested by other authors [23]. In Portugal large rearrangements correspond to $6 \%$ of the LDLR mutations, very similar as described in other populations [23].

APOB mutations are a rare cause of FH in Portugal compared to other countries [24]. An APOB mutation was only found in about $2 \%$ of all FH cases identified.

Our lab has developed a quick and simple method to analyse putative splicing mutations [9]. Whenever it is possible these alterations are studied to increase the scientific knowledge of the effect of these alterations and, most important, to determine if they are mutations causing disease or not. In this paper we report the functional effect of 3 mutations previously described [8] and 1 novel mutation is fully characterized. For one of the alterations reported in this paper (1846-1G>A), it was not possible to obtain a fresh blood sample for RNA extraction and cDNA analysis.

The cascade screening of relatives allowed a total of $404 \mathrm{FH}$ patients to be genetically identified in Portugal. This corresponds only to $2.02 \%$ of the estimated total number of Portuguese $\mathrm{FH}$ patients. Cascade screening in families proved to be an efficient method for the identification of $\mathrm{FH}$ patients. This approach allows a more time and cost effective diagnosis of FH diagnosis. A second phase of the project funded by the Portuguese Cardiology Society will start this year and will be dedicated to the cascade screening of the patients already identified as having FH. Until now the relatives screening has been low due to the inexistence of a research nurse able to collect blood samples from relatives living all over the country but, this difficulty will be overcome by the new grant. Also 
it will be contemplated the option of sample collection of epithelial cells by swabs or mouth wash solutions to screen for mutations in children or relatives specially those living abroad.

Clinician adhesion to the study has been increasing but it is still far from the expected, especially since major efforts to find external funding have been made to maintain the study free of cost for the patients and medical institutions.

The genetic identification of a mutation causing disease in FH patients, confirms the clinical diagnosis based on the plasma cholesterol levels determinations and provides an unequivocal diagnosis of the disease and allows the early identification of affected relatives. This is especially important for young patients since they can receive appropriate dietary and lifestyle advice and adequate therapeutic measures when necessary in order to reduce their risk of CHD. If adequate measures (counselling and therapeutic) are taken early enough the cardiovascular risk of young $\mathrm{FH}$ patients can decrease to equal to the general population.

As reported by the clinicians, in our population, the genetic diagnosis increases the patient adherence to treatment although, majority of the patients are not receiving adequate treatment as described elsewhere [25]. This is due to mainly three reasons: patients do not take the medication prescribed because, (1) they are not aware of theirs increased cardiovascular risk; (2) they have social-economics problems or (3) the clinicians are not prescribing the adequate treatment for patient with genetic condition. The overall result is that the cardiovascular risk of the majority of the Portuguese $\mathrm{FH}$ patient is not reduced. Awareness strategies to alert the patients and the health authorities have to be implemented at larger scale so cardiovascular prevention can be achieved.

\section{Acknowledgements}

The authors would like to thank Professor Anne Soutar for manuscript revision. The authors would also like to thank the technicians of the Clinical Chemistry Lab at the National Institute of Health, Lisbon for performing the biochemical tests. The authors are indebted to all index patients and relatives for participating in this study. The following grants are acknowledge: "Clinical and molecular characterization of Portuguese FH patients" Portuguese Society of Cardiology (2006-2009), “PIC/IC/83333/2007" Science and Technology Foundation (2009-2011) and SFRH/BD/27990/2006 (AC Alves, PhD grant) Science and Technology Foundation.

"The Portuguese FH Study" is being developed at the Grupo de Investigação Cardiovascular, Unidade de Investigação \& Desenvolvimento, Departamento de Promoção da Saúde e Doenças Crónicas, Instituto Nacional de Saúde Dr. Ricardo Jorge (INSA). Coordinator: Dr. Mafalda Bourbon. Clinical Consultant: Dra. Quitéria Rato. Clinical Genetics Consultant: Dra. Isabel Gaspar. Molecular Research: Dr. Mafalda Bourbon (principal investigator), Ana Catarina Alves, Ana Margarida Medeiros and Vânia Francisco, Grupo de Investigação Cardiovascular, Unidade de I\&D, DPSDC, INSA. Clinical Research: Dra. Henedina Antunes, Serviço de Pediatria, Hospital de São Marcos, Braga; Dra. Goreti Lobarinhas, Serv. Pediatria, Hosp. Sta Maria Menor, E.P.E., Barcelos; Dra. Natalina Miguel, Centro Hospitalar de Trás-os-Montes e Alto Douro, E.P.E., Vila Real; Dra. Helena Mansilha, Hosp. Central Especializado de Crianças Maria Pia (Centro Hospitalar do Porto, E.P.E.), Porto; Prof. António Guerra, Serv. de Pediatria, Hosp. de S. João, E.P.E., Porto; Dra. Ana Sofia Correia, Serv. de Cardiologia, Hosp. de S. João, E.P.E., Porto; Dra. Paula Martins, Serv. Cardiologia Pediátrica, Hosp. Pediátrico Coimbra, Coimbra; Dr. Lina Cardoso Ramos, Serv. Genética, Hosp. Pediátrico, Coimbra; Dr Paula Garcia, Unid. Doenças Metabólicas, Hosp. Pediátrico, Coimbra; Dr António Cruz, Serv. Pediatria, Hosp. Sto André, Leiria; Dra. Ana Gaspar, Serv Pediatria, Hosp. de Santa Maria, E.P.E., Lisboa; Prof. Heloísa Santos, Fundação Professor Fernando de Pádua, Lisboa; Dr. Isabel Gaspar, Serv. de Genética Médica, Hosp. de Egas
Moniz, Lisboa; Dr. João Sequeira Duarte, Serv. De Endocrinologia, Hosp. de Egas Moniz, Lisboa; Dra. Leonor Sassetti, Unid. De Adolescentes, Hosp. D. Estefânia, Lisboa; Dra. Sílvia Sequeira, Serv. Doenças Metabólicas, Hosp. D. Estefânia, Lisboa; Dra. Piedade Sande Lemos, Serv Pediatria, Hosp Amadora Sintra, Amadora; Dra. Renata Rossi, Serv. Cardiologia Pediátrica, Hosp. Sta. Cruz, Carnaxide; Dra. Margarida Bruges, Serv Nefrologia, Hosp. Sta. Cruz, Carnaxide; Dr. Miguel Mendes, Serv. Cardiologia, Hosp. Sta. Cruz, Carnaxide; Dr. Mário Amaro, Serv Medicina Interna, Hospital Garcia da Orta, Almada; Dr. José Manuel Feliz, Centro de Saúde do Seixal, Setúbal; Dra. Quitéria Rato, Serv. de Cardiologia, CHS, Hosp. de São Bernardo, Setúbal; Dra. Isabel Azevedo, Serv. de Med. Interna I, Hosp. Dos Marmeleiros, Funchal.

\section{Appendix A. Supplementary data}

Supplementary data associated with this article can be found, in the online version, at doi:10.1016/j.atherosclerosis.2010.07.012.

\section{References}

[1] Goldstein JL, Hobbs H, Brown MS. In: Scriver CR, Beaudet AL, Sly WS, Valle $\mathrm{D}$, editors. Familial hypercholesterolaemia. The metabolic basis of inherited disease, vol. II, 7th ed. New York: McGraw-Hill; 1995. p. 1981-2021.

[2] Soutar AK, Naoumova RP. Mechanisms of disease: genetic causes of familial hypercholesterolemia. Nat Clin Pract Cardiovasc Med 2007;4(4):21425.

[3] Austin MA, Hutter CM, Zimmern RL, Humphries SE. Genetic causes of monogenic heterozygous familial hypercholesterolemia: a HuGE prevalence review. Am J Epidemol 2004;160:407-20.

[4] Leigh SE, Foster AH, Whittall RA, Hubbart CS, Humphries SE. Update and analysis of the University College London low density lipoprotein receptor familial hypercholesterolemia database. Ann Hum Genet 2008;72(4):48598.

[5] Borén J, Ekström U, Ågren B, Nilsson-Ehle, Innerarity TL. The molecular mechanism for the genetic disorder familial defective apolipoprotein B100. J Biol Chem 2001;276(12):9214-8.

[6] Leigh SE, Leren TP, Humphries SE. Commentary PCSK9 variants: a new database. Atherosclerosis 2009;203(March (1)):32-3.

[7] Bourbon M, Rato Q. Estudo Português de Hipercolesterolemia Familiar: Apresentação do Estudo e Resultados preliminares. Rev Port Cardiol 2006;25(11):999-1013.

[8] Bourbon M, Alves AC, Medeiros AM, Silva S, Soutar AK. Familial hypercholesterolemia in Portugal. Atherosclerosis 2008;196(2):633-42.

[9] Bourbon M, Duarte MA, Alves AC, et al. Genetic diagnosis of familial hypercholesterolaemia: the importance of functional analysis of potential splice-site mutations. J Med Genet 2009;46(May (5)):352-7.

[10] Cenarro A, Jensen HK, Casao E, et al. Identification of recurrent and novel mutations in the LDL receptor gene in Spanish patients with familial hypercholesterolemia. Mutations in brief no. 135. Hum Mutat 1998;11(5):413 [online].

[11] Nauck MS, Köster W, Dörfer K, et al. Identification of recurrent and novel mutations in the LDL receptor gene in German patients with familial hypercholesterolemia. Hum Mutat 2001;18(August (2)):165-6.

[12] Leitersdorf E, Reshef A, Meiner V, et al. A missense mutation in the low density lipoprotein receptor gene causes familial hypercholesterolemia in Sephardic Jews. Hum Genet 1993;91(March (2)):141-7.

[13] Hobbs HH, Brown MS, Goldstein JL. Molecular genetics of the LDL receptor gene in familial hypercholesterolemia. Hum Mutat 1992;1(6):445-66.

[14] Langenhoven E, Warnich L, Thiart R, et al. Two novel point mutations causing receptor-negative familial hypercholesterolemia in a South African Indian homozygote. Atherosclerosis 1996;125(August (1)):111-9.

[15] Hobbs HH, Russell DW, Brown MS, Goldstein JL. The LDL receptor locus in familial hypercholesterolemia: mutational analysis of a membrane protein. Annu Rev Genet 1990;24:133-70.

[16] Wang J, Ban MR, Hegele RA. Multiplex ligation-dependent probe amplification of LDLR enhances molecular diagnosis of familial hypercholesterolemia. J Lipid Res 2005;46(February (2)):366-72.

[17] Hattori H, Nagano M, Iwata F, et al. Identification of recurrent and novel mutations in the LDL receptor gene in Japanese familial hypercholesterolemia. Mutation in brief no. 248. Hum Mutat 1999;14(1):87 [online].

[18] Fouchier SW, Kastelein JJ, Defesche JC. Update of the molecular basis of familial hypercholesterolemia in The Netherlands. Hum Mutat 2005;26(December (6)):550-6.

[19] Mozas P, CastilloS, Tejedor D, et al. Molecular characterization of familial hypercholesterolemia in Spain: identification of 39 novel and 77 recurrent mutations in LDLR. Hum Mutat 2004;24(August (2)):187.

[20] Soutar AK, Knight BL, Patel DD. Identification of a point mutation in growth factor repeat $C$ of the low density lipoprotein-receptor gene in a patient with homozygous familial hypercholesterolemia that affects ligand binding and 
intracellular movement of receptors. Proc Natl Acad Sci USA 1989;86(June (11)):4166-70.

[21] Takada D, Emi M, Ezura Y, et al. Interaction between the LDL-receptor gene bearing a novel mutation and a variant in the apolipoprotein A-II promoter: molecular study in a 1135 -member familial hypercholesterolemia kindred. J Hum Genet 2002;47(12):656-64.

[22] Liyanage KE, Hooper AJ, Defesche JC, Burnett JR, van Bockxmeer FM. High-resolution melting analysis for detection of familial ligand-defective apolipoprotein B-100 mutations. Ann Clin Biochem 2008;45(March (Pt 2)):170-6.
[23] Taylor A, Martin B, Wang D, et al. Multiplex ligation-dependent probe amplification analysis to screen for deletions and duplications of the LDLR gene in patients with familial hypercholesterolaemia. Clin Genet 2009;(June)

[24] Humphries SE, Norbury G, Leigh S, Hadfield SG, Nair D. What is the clinical utility of DNA testing in patients with familial hypercholesterolaemia? Curr Opin Lipidol 2008;19(August (4)):362-8.

[25] Alves AC, Medeiros AM, Francisco V, et al. Molecular diagnosis of familial hypercholesterolaemia: an important tool for cardiovascular risk stratification. Rev Port Cardiol May; in press. 